\title{
Modeling Marketing Dynamics by Time Series Econometrics*
}

\author{
KOEN PAUWELS ${ }^{\dagger}$ \\ Assistant Professor, Tuck School of Business at Dartmouth \\ IMRAN CURRIM \\ Chancellors Professor, Graduate School of Management, University of California, Irvine \\ MARNIK G. DEKIMPE \\ Professor, Catholic University Leuven and Erasmus University Rotterdam \\ ERIC GHYSELS \\ Bernstein Distinguished Professor of Finance, Kenan-Flagler Business School, UNC Chapel Hill \\ DOMINIQUE M. HANSSENS \\ Bud Knapp Professor of Marketing, UCLA Anderson School of Management \\ NATALIE MIZIK \\ Assistant Professor, Graduate School of Business, Columbia University \\ PRASAD NAIK \\ Associate Professor, Graduate School of Management, University of California, Davis
}

Koen.h.pauwels@dartmouth.edu

\begin{abstract}
This paper argues that time-series econometrics provides valuable tools and opens exciting research opportunities to marketing researchers. It allows marketing researchers to advance traditional modeling and estimation approaches by incorporating dynamic processes to answer new important research questions. The authors discuss the challenges facing time-series modelers in marketing, provide an overview of recent methodological developments and several applications, and highlight fruitful areas for future research. This discussion is based on the First Annual Conference on 'Modeling Marketing Dynamics by Time Series Econometrics' at the Tuck School of Business at Dartmouth, Hanover, New Hampshire, USA on September 16-17, 2004.
\end{abstract}

Keywords: time series models, marketing dynamics, data richness, Lucas critique, impulse response functions

Time-series econometrics has made several important contributions in fundamental areas of marketing. As reviewed in Dekimpe and Hanssens (2000, Table 1), time-series (TS) techniques were initially used in marketing (1) for forecasting purposes, (2) to determine the temporal ordering among variables through Granger-causality tests, or (3) to determine the over-time impact of marketing variables (e.g. through transfer-function analysis). Recently,

*Insights from the First Annual Conference, Tuck School of Business at Dartmouth.

${ }^{\dagger}$ Corresponding author. 
Table 1. Overview of Challenges and Proposed Approaches

\begin{tabular}{|c|c|c|}
\hline Challenges & Approaches & Some relevant papers \\
\hline \multicolumn{3}{|l|}{ 1. Data Richness: } \\
\hline \multicolumn{3}{|l|}{ 1.1 Aggregation } \\
\hline Over Consumers & Segment-level response & Lim et al. (2004) \\
\hline \multirow[t]{2}{*}{ Over Time Periods } & Optimal data interval & Tellis and Franses (2004) \\
\hline & Mixed data sampling & Ghysels et al. (2003) \\
\hline \multirow{2}{*}{$\begin{array}{l}\text { 1.2 Parameterization } \\
\text { (Stores, SKUs) }\end{array}$} & Pooling parameters & Horváth et al. (2004) \\
\hline & Dimension reduction & Pauwels et al. (2004a) \\
\hline 1.3 Pruning & Bias-reducing techniques & $\begin{array}{l}\text { Zanutto and Bradlow (2001) } \\
\text { Andrews and Currim (2004) }\end{array}$ \\
\hline \multirow[t]{4}{*}{ 2. Lucas Critique } & Super-exogeneity tests & $\begin{array}{l}\text { Franses (2005) } \\
\text { Naik and Raman (2003) }\end{array}$ \\
\hline & Varying-parameter models & Van Heerde et al. (2005) \\
\hline & Spectral analysis & Naik et al. (1998) \\
\hline & & Bronnenberg et al. (2004) \\
\hline 3. Broadening & Kalman Filter & Naik et al. (1998) \\
\hline \multirow[t]{2}{*}{ Techniques, } & Spectral band-pass analysis & Deleersnyder et al. (2004) \\
\hline & Bayesian error-correction & Fok et al. (2004) \\
\hline \multirow[t]{5}{*}{ and Marketing problems } & Strategic Foresight & Naik et al. (2005) \\
\hline & Marketing-Finance & Mizik and Jacobson (2004b) \\
\hline & interface & Pauwels et al. (2004b) \\
\hline & & Joshi and Hanssens (2004) \\
\hline & Internet $\mathrm{Bid}$ analysis & Naik and Jap (2004) \\
\hline \multirow[t]{2}{*}{ 4. Asymmetric Response } & Add error correction terms & Simon (1982) \\
\hline & & Hansens and Levien (1983) \\
\hline 5. Definition & Define long-run elasticity & Dekimpe and Hanssens (1999) \\
\hline \multirow[t]{3}{*}{ Consistency } & & Nijs et al. (2001) \\
\hline & & Pauwels et al. (2002) \\
\hline & & Wierenga and Horváth (2004) \\
\hline \multirow[t]{4}{*}{ 6. Changing Dynamics } & Structural breaks & Deleersnyder et al. (2002) \\
\hline & Dynamic IRFs & Pauwels and Srinivasan (2004) \\
\hline & Moving Windows & Yoo (2004) \\
\hline & & Pauwels and Hanssens (2004) \\
\hline
\end{tabular}

there has been a renewed interest in the use of TS-techniques, not only to demonstrate the existence of certain substantive marketing phenomena, but also to derive empirical generalizations on their relative size and frequency of occurrence. ${ }^{1}$ Studies in the former tradition have, for example, shown that time-series techniques can be used to quantify short-term, long-term and permanent effects (Dekimpe and Hanssens, 1995), momentum (Bronnenberg et al., 2000), business-as-usual, hysteresis and escalation (Dekimpe and Hanssens, 1999), ad copy and repetition wearout (Naik et al., 1998), half-life of ads (Naik, 1999), synergy (Naik and Raman, 2003), and strategic foresight (Naik et al., 2005). Studies in the latter tradition include Nijs et al. (2001), Pauwels and Srinivasan (2004), and Srinivasan et al. (2004). A typical design in these studies is a two-stage approach, where, the same time-series technique is first applied to a multitude of brands and/or product categories, after which one tries to explain the observed variability in various summary statistics (e.g. short or long-run elasticity estimates) through a number of marketing-theory based hypotheses. To this end, 
a more marketing-theory grounded approach to TS modeling was adopted. Moreover, other key challenges identified in Dekimpe and Hanssens (2000), such as the lack of longitudinal data and the lack of dedicated time-series software, have been overcome in recent years.

Still, important research opportunities and challenges remain, which were summarized in a number of challenges in the presentation by Dekimpe and Hanssens, and elaborated upon by various other presentations as well as round-table discussions, at the conference 'Modeling Marketing Dynamics by Time Series Econometrics', held at the Tuck School of Business at Dartmouth in September 2004. These challenges (summarized in Table 1) are the focus of this paper. ${ }^{2}$

\section{Challenge 1: Dealing with Recent Data Richness}

Dekimpe and Hanssens (2000) identified the shortage of good time-series data as one of the main obstacles to the initial diffusion of time-series methods into the marketing literature. However, they acknowledged that recent developments, such as the growing availability of longer series of scanner data, considerably alleviated this concern (see e.g., Dekimpe et al., 1999; Pauwels et al., 2002; Pauwels and Srinivasan, 2004; Nijs et al., 2001 for recent applications of TS-techniques to scanner-based data). ${ }^{3}$

However, data have not only become available over longer time spans, they also became available at ever more disaggregate levels. This enabled researchers to build intricate dynamic models at the individual-store level (e.g., Srinivasan et al., 2003), the consumersegment level (Lim et al., 2004), or even at the individual SKU-level (e.g., Macé and Neslin, 2004; Pauwels et al., 2004). Moreover, data now become available at ever smaller time intervals. Still, this recent data explosion has also resulted in a set of new concerns, such as (i) the issue of data aggregation in time-series models, (ii) potential over-parameterization when adopting a systems approach, and (iii) the common (yet not consistent) practice of data pruning.

\subsection{Data Aggregation}

Cross-sectional heterogeneity and aggregation bias have been important subjects in both economics (Pesaran and Smith, 1995) and marketing (e.g., Allenby and Rossi, 1991; Christen et al., 1997). Recent marketing time-series (TS) studies have taken a variety of approaches to deal with this issue. While most studies (perhaps at the explicit request of reviewers), acknowledge the potential bias that emerges when using arithmetically averaged data in the estimation of non-linear models, few recognize that the neglect of (slope) heterogeneity across the entities over which the data are averaged is even more serious in dynamic models (a notable exception is Horváth and Wieringa, 2004). Indeed, in models with serially-correlated lagged endogenous variables, incorrectly ignoring coefficient heterogeneity induces serial correlation in the error term, which in turn results in inconsistent parameter estimates (see Pesaran and Smith, 1995 for an in-depth discussion). This applies to both linear and nonlinear models. As such, the approach used in Nijs et al. (2001) and Srinivasan et al. (2004) to compare the IRFs of linear and multiplicative models may not be fully informative on the presence/absence of aggregation bias in dynamic models. 
Horváth and Wieringa (2003) advocate the use of preliminary pooling tests to determine the appropriate level of parameter heterogeneity that should be allowed for. In their empirical application (see also Horváth et al., 2004), a fixed-effects VAR model is used where different intercepts but common slopes are estimated across more than 20 stores. More research is needed, however, on how to proceed when the preliminary tests indicate that the slopes cannot be treated as homogenous (we elaborate on this issue below).

To further complicate matters, aggregation can take place across multiple dimensions: across the stores in a country (Nijs et al., 2001), across the stores in a chain (Srinivasan et al., 2004) or across the SKUs of a brand (Pauwels et al., 2004a). Thus far, studies that focus on the potential bias arising from aggregating across one dimension, have tended to ignore that the same problem may also arise because of the aggregation across the other dimensions. For example, even if one would estimate response models at the SKU level in individual stores, there might still be the issue whether all consumer segments have the same shortand/or long-run response parameters. Such heterogeneity was demonstrated at the Tuck conference by Imran Currim, who obtained different response patterns to price promotions for heavy versus light users in a category level analysis, and for loyal versus switching segments in a brand level analysis. First, light users are found to have longer adjustment periods and larger adjustment effects but smaller total effects for perishable products. For non-perishable products, heavy users are found to exhibit a post-promotion dip, which reduces the total effect of the promotion relative to light users. Moreover, consumers loyal to other brands have longer adjustment periods, and larger adjustment and total effects than either consumers loyal to the focal brand or switchers. Finally, segment-level VARX models were found to improve forecasts over their aggregate counterparts for two of four product categories studied. When segment-level VARX models do not offer better forecasts than their aggregate counterparts, the segment-level RMSE is usually close to its aggregate-level counterpart, so that not much is lost in using segment-level VARX models (Lim et al., 2004). Discussion revealed that future research could investigate whether price promotions can pull consumers from one segment to the other. In addition, while a priori segmentation (e.g., heavy vs. light users, loyals vs. switchers) results in insights which are useful for marketing managers, it may not be the most statistically efficient way to segment consumers, because it does not necessarily maximize (minimize) differences across (within) segments. Consequently, it may be useful to develop a household-level approach based on a posteriori segmentation. Obviously, more research is needed on how to best accommodate these various sources of cross-sectional heterogeneity in time-series models.

Thus far, we focused on cross-sectional aggregation across stores, SKUs or customers. However, data have not only become available on smaller entities, but also at ever smaller time intervals. This opens up a whole new set of research opportunities. Two of them were specifically considered at the Tuck conference: Tellis and Franses (2004) reconsidered the optimal data interval issue for econometric models of advertising carryover, while Ghysels (2004) explored the econometric consequences of mixed data sampling models, i.e., where different variables have a different data-collection frequency. Indeed, most timeseries and marketing models to date assume a common frequency of data collection across all variables in the model. However, nowadays, data on market performance and marketing actions may come in different frequencies (e.g., weekly for price and sales, monthly for 
advertising, quarterly for firm earnings). Ghysels et al. (2003a) developed Mixed Data Sampling (MIDAS) Regression methods to deal with this issue. This approach constructs regressions combining data with different sampling frequencies. In essence, MIDAS constructs a polynomial of coefficients on lagged independent variables, governed by a small set of hyperparameters. Numerous applications are already available in the finance area (see e.g., Forsberg and Ghysels, 2004; Ghysels et al., 2003b, c). However, in current MIDAS applications, the right-hand side variable is the most-frequently sampled variable. In a marketing setting, this may involve linking weekly marketing actions to quarterly firm performance, or using very fine-tuned Internet marketing actions to explain slower changing (and less frequently sampled) consumer attitudes. However, other marketing settings face the opposite problem, as independent variables such as advertising are assessed at coarser (e.g.) monthly levels, and used to explain performance (e.g., sales) at weekly levels. To this end, a 'reverse MIDAS' approach needs to be developed.

\subsection{Level of Parameterization}

A key contribution of recent time-series applications in marketing has been their systems approach to dynamic interactions. In particular, VAR models have become quite popular in this respect. However, as the number of endogenous variables increases, the number of parameters tends to quickly become unwieldy. Specifically, a VAR model with $n$ endogenous variables and of lag order $p$ would require the estimation of $p n^{2}$ autoregressive parameters.

Initial VAR applications in marketing tended to limit the number of endogenous variables. Dekimpe and Hanssens (1995), for example, considered two and three-equation models. Pauwels and Srinivasan (2004), in contrast, incorporated nine endogenous variables, while including 9 other marketing support variables as exogenous variables. This evolution towards ever larger VAR models is motivated partly by the longer time-series that have become available (e.g., 76 observations in Dekimpe and Hanssens versus 399 in Pauwels and Srinivasan), ${ }^{4}$ but also by the flexibility of these models to incorporate several kinds of dynamic interactions. Obviously, by including more endogenous variables, the danger of omittedvariable biases diminishes, but the reliability of the individual parameter estimates will be reduced as the observation-to-parameter ratio becomes smaller. This holds especially in settings that already exhibit a high degree of correlation (both across brands/SKUs and between the various lags of the same variable). More research on this trade-off is called for.

More research is also needed on the relative value of alternative approaches that have been used in recent marketing studies to limit the number of parameters to be estimated, such as (i) re-estimating the model with all parameters with an initial $t$-value smaller than one in absolute value restricted to zero (e.g., Dekimpe and Hanssens, 1995), (ii) having a subset of the variables as endogenous, while incorporating the remaining potentially relevant variables as exogenous control variables, followed by (iii) extensive validation exercises in which each time some of the initially exogenous variables are endogenized (e.g., Nijs et al., 2001; Srinivasan et al., 2004), (iv) the use of pooling techniques to enhance the efficiency of the parameter estimates (see e.g., Horváth et al., 2004; Horváth and Wieringa, 2003), and (v) the use of dimension-reduction techniques as explored in Pauwels et al. (2004a). 
The latter two approaches offer a refreshing perspective that may prove particularly useful as the level of aggregation becomes smaller and smaller, such as the individual-store level or the individual-SKU level. Indeed, none of the former three approaches seems well suited when dealing with hundreds of stores and/or SKUs.

Horváth and co-authors conduct a pooling test across multiple stores, and subsequently estimate a pooled VAR model with fixed effects to account for heterogeneity in the intercepts. ${ }^{5}$ Even though their approach increases the efficiency of the (pooled) autoregressive parameter estimates, more research is needed on how to deal with evolving variables (which are now pruned from further analysis, cf. infra), or on how to proceed if the initial overall pooling test is rejected. Should one then proceed by applying the same test on a smaller (a priori defined) subset of stores (e.g., a size- or format-based segmentation), or should one perform pooling tests on subsets of the autoregressive parameter estimates (e.g., separate tests on, respectively, the diagonal and the off-diagonal elements)?

Pauwels et al. (2004a) take a completely different perspective in their Factor VAR-model for SKU prices and sales. This approach captures both the cross-section and the longitudinal variation in data with high dimensions, as they jointly estimate the number of factors, the factor structure and the dynamics. New to the econometric literature, the Factor-VAR allows for specific marketing issues, such as contemporaneous effects of prices on sales, and the integration of marketing theory in a confirmatory factor analysis. Simulations show the consistency and efficiency of the proposed approach. The application to the soda category revealed that the high correlation in SKU-data allows a summary in a few factors, but that the simplest SKU-indices per brand fail to account for negative price correlation across product formats. Moreover, questions still arise on the factor structure and on the interpretation of factors. First, should the factor analysis be exploratory (as applied in economics), or confirmatory, given the extent of marketing theory (e.g., per brand, format, flavor, etc.)? A fit comparison between alternative models may enable selection of the most appropriate factors structure. Second, more research is needed on whether a relatively "free" factor structure for prices might reveal better ways to compute price indices, while it might be better to restrict the structure of sales for ease of interpretation.

Finally, Leeflang and Wittink (1992) have advocated the use of preliminary (bivariate) Granger-causality tests to limit the number of variables to be included in the final model specification. However, as the number of potential variables increases, the number of tests required to cover all possible combinations rapidly becomes excessive, causing individual $p$-values to suffer from the well-known multiple-testing problem. Lemmens et al. (2005) therefore explore the usefulness of multivariate testing procedures.

More research is needed, however, on the relative merits of each of the aforementioned procedures to limit the number of variables to the included into the model (and hence, the number of parameters to be estimated).

\subsection{Data Pruning}

In response to the increasing number of brands, stores and/or SKUs, it has become common practice to prune the available data to a more manageable number (Andrews and 
Currim, 2004; Zanutto and Bradlow, 2001). For example, Nijs et al. (2001) consider the competitive reactivity among the top-five brands in the market, Pauwels et al. (2002) decompose the long-term effects of price promotions using data from the largest store in four different chains, while Srinivasan et al. (2004) look at the profitability of price promotions for the three best-selling brands in 21 product categories. The well-known 80/20 rule may be used as further motivation for this pruning practice, as a small set of brands often captures most of the market.

This data pruning practice may have a number of undesirable consequences. First, the resulting empirical generalizations may not be representative for all brands, but only for the more successful brands. In many markets, however, the number of less successful brands outnumbers the more successful ones, and one could argue that managers of the former have a higher need for well-founded advice. Second, the unfortunate practice of using a large variety of different data-pruning rules (e.g., top five versus top three) diminishes the comparability of the findings. Even though each individual study is careful in stating its own pruning rule, the danger is imminent that these intricacies get lost when citing the results (e.g., the resulting average response or reactivity elasticity), or when meta-analytically combining results from multiple studies into updated empirical generalizations. Finally, Zanutto and Bradlow (2001) demonstrate, in the context of consumer choice models, how data pruning might lead to significantly biased parameter estimates (and hence, potentially different managerial implications) compared to models that are estimated on the full data set. While the Zanutto and Bradlow (2001) study is based on real data wherein true parameter estimates are unknown, Andrews and Currim (2004) conduct a simulation wherein true parameter estimates are known. They investigate entity aggregation (analyses at brand vs. brand-size, vs. SKU levels) as well as data pruning decisions in the context of consumer choice models, and find that such data preparation decisions can have significant implications for the assessment of consumer response to price and promotion. Even though more research is needed on this issue, one might expect a similar bias in the context of dynamic (time-series) models. Andrews and Currim (2004) and Zanutto and Bradlow (2001) describe several bias reducing (or even eliminating) strategies that are potentially useful in the context of time-series models.

Data pruning is often motivated by the aforementioned concerns of over-parameterization. Data pruning, however, may also result because of data characteristics and/or preliminary test outcomes. For example, when estimating models at very disaggregate levels, one is likely to encounter short, interrupted time series (see e.g., Macé and Neslin, 2004 in the context of SKUs), or models where one or more variables show limited variability (see e.g., Horváth et al., 2004 in the context of store-level promotional models). In both instances, the respective SKU or stores tend to be ignored from further analysis. Still, one could argue that precisely those SKUs which were discontinued might be most informative as to what marketing is less effective. Finally, recently developed pooling techniques (see e.g., Horváth et al., 2004; Horváth and Wieringa, 2003) and variance-decomposition techniques (see e.g., Srinivasan et al., 2003) tend to require stationary series. Again, it is then customary to ignore all stores or brands where preliminary unit-root tests showed evolutionary or $I(1)$ behavior in one or more key variables. However, brands/stores whose performance is gradually improving or deteriorating, or which are involved in a price war and/or advertising escalation, may 
intrinsically be the most interesting cases. Their omission therefore hardly seems to be an optimal procedure.

\section{Challenge 2: Dealing with the Lucas Critique}

Most time-series models are intrinsically reduced-form models, which makes them susceptible to the Lucas Critique when they are used for policy simulations (see Franses, 2005 and Van Heerde et al., 2005 for an in-depth discussion on this issue). In a nutshell, the Lucas critique states that policy (e.g., marketing strategy) changes are likely to alter the parameters and/or structure of econometric (reduced-form) models, making the pre-change parameter estimates less suited to evaluate the impact of the policy change.

Of course, formal tests of parameter constancy can be carried out (e.g., Brown et al., 1975). If parameters are deemed constant, market data present little evidence to support the hypothesis of "change in parameter estimates". If the hypothesis of parameter constancy is rejected, one could alleviate the problem by formulating formal time-varying parameter models (e.g., Naik et al., 1998). These could, for example, be estimated via state space methods (e.g., Durbin and Koopman, 2001). However, as indicated in Van Heerde et al. (2005), varying-parameter models may only shift the problem from assuming constant parameters to assuming constant response functions.

Another approach to circumvent this critique has been to focus on impulse-response function analysis, and to explicitly state the assumption that the unexpected change or shock does not alter the nature of the data-generating process (cf. Dekimpe et al., 1999, p. 271). This limits the sensitivity to the Lucas critique, but also limits the scope of the marketing changes one can investigate (i.e., recurring, small shocks rather than irregular, structural changes). Other researchers have opted to nevertheless use the reduced-form parameters to carry out conditional forecasting experiments (e.g., Pauwels, 2004). However, the more drastic (and perhaps more interesting) the forecasting experiment, the more it becomes susceptible to the Lucas critique.

Even though this is, unfortunately, done rarely in marketing (see Naik and Raman, 2003 for a notable exception), one could also implement super-exogeneity tests to determine whether or not a given (historical) policy change altered the response parameters of interest. Many of these tests (which again center around the constancy of various parameters of interest) have been developed in the context of VAR and cointegration type models, which makes it even more surprising that they have been largely ignored in marketing applications of these techniques.

A fourth, thus far little explored, approach to deal with the Lucas critique is to bring more structure into time-series models. The structural VAR models introduced in Pauwels (2004) are a first step in that direction. One could, however, also approach the issue from a totally different angle, and try to better incorporate (short- and long-run) dynamics into structural models. Indeed, advocates of the structural NEIO models have argued that these models are insensitive to the Lucas critique (see e.g., Kadyali et al., 2001). However, as most of these models are static, they are very likely to be subject to a specification bias. ${ }^{6}$ An intermediate approach was recently adopted in Bronnenberg et al., (2004). Rather than 
bringing structure into time-series models or bringing dynamics into structural models, they first decomposed (using spectral techniques, cf. infra) the time series into different frequencies (planning cycles), and then estimated a static structural model on each filtered series. In so doing, time-series and structural approaches were used as complementary, rather than as competing, approaches. Further research on ways to reconcile the dynamic flexibility of time series models with the need for more structure in order to immunize policy implications from the Lucas Critique is both a major challenge and a fruitful area for future research.

Related to this issue is the notion that models used for policy simulations should also have good descriptive (within-sample) and forecasting (out-of-sample) properties (Franses, 2005a, b). Time-series studies traditionally emphasized both issues. ${ }^{7}$ Unfortunately, they have received less attention in many of the more recent TS applications in marketing. For example, many of the important diagnostics for econometric (TS) models identified in Franses (2005a, b), such as hold-out sample fit, appropriateness of functional-form and distributional assumptions and parameter stability, tend to no longer be formally reported. We concur with Franses that it would be advantageous for TS modelers to go back to their roots, and again pay closer attention to these issues.

\section{Challenge 3: Broadening the Scope of Techniques and Marketing Problems}

In recent years, various VAR-based persistence models have been developed to study the over-time effectiveness of different marketing-mix instruments, such as price promotions (e.g., Pauwels et al., 2002), advertising (Dekimpe and Hanssens, 1995), distribution (Bronnenberg et al., 2000), and new-product activity (Pauwels et al., 2004b; Pauwels and Srinivasan, 2004).

However, time-series techniques are not limited to VAR-based persistence-models, and a wider range of marketing problems could be investigated. For example, the Kalman-filter approach may offer many distinct advantages to not only estimate time-series models, but also understand managerial decision-making. For example, a long-standing and unresolved marketing problem (Sasieni, 1971, 1989) is that managers often use pulsing media schedules (i.e., spend on advertising a few weeks of the year, and not spend in other weeks), whereas almost all advertising time-series models recommend that a constant spending schedule is optimal. By incorporating the phenomenon of wearout (due to both copy obsolescence and ad repetition), Naik et al. (1998) shed light on this discrepancy between the practice of pulsing and the model-implied constant spending policy. The Kalman filter facilitates the estimation of such dynamic models in which the unknown states-namely the formation of goodwill and the wearout of ad effectiveness-are intimately coupled and these dependencies are driven by managerial actions.

Marketing-mix planning presents another important context for such dynamic dependencies and interactions. Specifically, brand managers need to account for interactions between marketing activities as well as interactions among competing brands. By recognizing interaction effects between activities, managers can consider inter-activity tradeoffs and/or synergy effects in planning their marketing-mix strategies. Moreover, by recognizing 
interactions with competitors, managers can incorporate strategic foresight in their planning, which requires them to "look forward" and "reason backwards" in making optimal decisions. Looking forward means that each brand manager anticipates how other competing brands are likely to make future decisions and then, by reasoning backwards, deduces one's own optimal decisions in response to the best decisions to be made by all other brands. The joint consideration of interaction effects and strategic foresight in planning marketing-mix strategies was studied by Naik et al. (2005). They developed not only the marketing-mix algorithm to obtain marketing-mix plans with strategic foresight, but also a continuous-discrete estimation method to calibrate dynamic oligopoly models using market data. The latter method exploits Kalman filtering ideas to estimate continuous-time models using discrete-time market data. The empirical results show that, in the absence of strategic foresight, managers are likely to under-spend on advertising and over-spend on promotions. Thus, a wider range of time-series applications in marketing can be studied via the Kalman filter and related state space models (see recent books by Shumway and Stoffer, 2000; Durbin and Koopmans, 2001).

Similarly, almost all currently available marketing applications are situated in the time domain, and much less attention has been given to the spectral approach, which is popular in engineering (see e.g., Priestley, 1981). Recently, Bronnenberg et al. (2004) have used a spectral approach to demonstrate that cross-brand price reactivity differs across different planning horizons, while Deleersnyder et al. (2004) use band-pass filters developed in the spectral domain to isolate the business-cycle component in the diffusion path of consumer durables.

As there is increasing evidence that the same relationship need not hold among two variables at different frequencies, various substantive marketing problems may warrant further investigation along that dimension. For example, Lemmens et al. (2004) propose to decompose Granger causality over the spectrum. Given that Granger-causality testing has been a key application area for TS modeling in marketing (see Dekimpe and Hanssens, 2000 for a review), their testing procedure could lead to additional insights in some of the substantive areas where conventional (time-domain based) Granger-causality tests have been used.

Finally, also an integration of time-series techniques with the increasingly popular Bayesian research tradition may offer interesting opportunities. Fok et al. (2004), for example, develop a Hierarchical Bayes Error Correction Model to study the dynamic effects of price promotions, while Litterman (1984) argues that Bayesian VAR models are less susceptible to the aforementioned Lucas Critique.

Two recent developments may offer interesting opportunities to broaden the scope of marketing problems studied through time-series analysis: the increasing attention for the marketing-finance interface, ${ }^{8}$ and the emergence of Internet data sources. The former has recently been studied in Pauwels et al. (2004a), where investor reactions to auto companies' new product introductions and price promotions are contrasted, and by Joshi and Hanssens (2004), who examine the influence of advertising campaigns on the valuation of firms in the personal computer industry. At the Tuck conference, Natalie Mizik showed that the focus on firm current earnings may provide perverse incentives for managers to emphasize shortterm results over long-term profits. This myopic management involves deleting or delaying 
marketing actions that benefit the firm in the long run (such as R\&D), but hurt current earnings due to higher costs. Evidence of this behavior was found at times of Seasoned Equity Offerings (SEO), which present a strong motivation for managers to artificially inflate current earnings in hopes of increasing stock price. In a paper with Robert Jacobson, she models the dynamics of firm accounting performance and resource allocation patterns and shows that some firms experience positive ROI and negative R\&D and SG\&A shocks around SEO, and that those firms have lower earnings and stock return in subsequent years. Financial markets appear unable to completely distinguish myopic firms and as a result discount earnings implications for all firms. This, in turn, puts pressure on all managers concerned about current stock price, but unable to provide alternative signals of longterm performance, to overemphasize current-term accounting performance results. To end this vicious circle, long-term marketing metrics can play a key role as quantifiable and verifiable signals of future firm performance, as they help differentiate firms engaging in myopic behaviour from those managing for the long term. Marketing metrics that could help achieve these goals are, for example, brand assets, new product pipeline, perceived quality and customer retention (or churn).

The emergence of Internet data sources also offer a new impetus to the use of time-series techniques in marketing. As a case in point, Naik and Jap (2004) developed BidAnalyzer as a model to forecast and update bid-price information in real-time as an online auction progresses. Specifically, bid-price distributions of heterogeneous bidders in online reverse auctions are estimated, which allows them to demonstrate that the pressure to decrease bid prices is high when bidding frequency decreases, and when an auction begins or approaches its end. Their approach was shown to perform very well: it can accurately predict bid prices after a quarter of the auction time, and the ending bid for each bidder after half the auction time.

\section{Challenge 4: Allowing for Asymmetries in Market Response}

Market response models often assume a symmetric response pattern, e.g., the numerical sales impact of a marketing spending increase or decrease is the same in absolute value. While some authors have proposed more general, asymmetric response patterns (e.g., Little, 1979), they are rarely used in practice, specifically on time-series data. A notable exception is the ADPULS model of advertising response proposed by Simon (1982), which advances the notion that the start of an advertising campaign has a differential sales impact above and beyond its level effect. This effect was confirmed in empirical work on the media spending effects on military recruiting by Hanssens and Levien (1983).

Modern time-series methods such as VAR models have not investigated such important asymmetries. Consequently, the over-time impact of a positive marketing shock in a system of consumer and competitive response is still considered to be the equivalent of a negative shock impact in absolute value. Marketing management, however, often believes that discontinuation of marketing investments may have a slowly eroding sales effect which is different from the typically faster impact of a newly initiated marketing campaign. When seen in an evolving market environment, such a condition could give rise to a new form 
of asymmetric long-term equilibrium between sales performance and marketing spending: while higher marketing spending may not result in higher equilibrium sales, lower spending does result in lower equilibrium sales. A behavioral explanation for such asymmetry may be that the lower spending is perceived as a signal of weakening brand support, which results in lower trade support, despite the fact that consumer response to higher spending is no longer evident. VAR models may, for example, have to be extended with additional error correction terms that capture these asymmetric long-term effects.

\section{Challenge 5: Consistency in Definitions}

The marketing discipline as a whole, and the time-series domain in particular, would benefit highly from a higher level of definitional consistency. As a first example, consider the frequently-used terms of short- and long-run effectiveness. Not only does the interpretation of these terms differ from the ones used in dynamic individual-choice models (e.g. Mela et al., 1997), there is also no consistency within the recent, predominantly VAR-based, timeseries literature itself. For example, Dekimpe and Hanssens $(1995,1999)$ interpret the value to which an Impulse Response Function (IRF) converges as long-run effect. Others equate long-run effectiveness with the area under the IRF (Lim et al., 2004). Similarly, there is no consensus on whether the combined impact during the adjustment period (i.e. the time it takes before a new equilibrium is reached) should also incorporate the instantaneous effect. Even though each individual study clearly indicates its own definition/interpretation, this lack of definitional consensus across studies does not facilitate the comparability of their findings or the emergence of empirical generalizations.

Another frequently-used concept is the elasticity concept, as it is a unit-free measure that enables cross-brand or cross-category comparisons. Some studies estimate elasticities at the mean from linear models, while others use log-log models. As for the latter, some studies (see e.g. Nijs et al., 2001) directly sum the IRF coefficients to arrive at a combined elasticity over a given time horizon, while Wierenga and Horváth (2004) first convert log-forecasts into level forecasts before deriving the corresponding elasticities. Each of these procedures may result in somewhat different estimates. Moreover, Nijs et al. (2001) define the primarydemand elasticity of a price promotion at the country level, Srinivasan et al. (2004) do so at the chain level, while Srinivasan et al. (2003) operationalize the concept at the store level. Again, this lack of uniformity will hamper the comparability of their substantive findings, and the intricacies of each definition may easily get lost in future referencing.

\section{Challenge 6: Capturing Changing Dynamics}

Unit-root tests followed by VAR modeling in either levels or differences are now common in the market response literature (see Hanssens et al., 2001 for a review). Once a regime of either evolution or stationarity has been assessed, it is commonly assumed that this regime holds for the entire time sample under study, unless there are clearly identifiable structural breaks that separate, for example, two stationary subperiods (Deleersnyder et al., 2002; Pauwels and Srinivasan, 2004). 
However, even in the absence of structural breaks, we know that market responsiveness may not be the same over time. For example, Parsons (1974) argued that advertising effectiveness declines over the life cycle of a product, and subsequent empirical studies have confirmed this pattern. This creates new challenges for the use of modern time-series techniques on marketing data.

One promising avenue for modeling the changing nature of shocks in time series is the "dynamic impulse response function" proposed by Yoo (2004). Using a Kalman-filter estimator, Yoo obtains persistence levels of shocks that depend on the timing of each shock. The common impulse response function is a special case where shock timing has no effect on the persistence level. Yoo's empirical analysis shows, for example, that the persistence of price shocks on sales of an established brand of yoghurt is much higher after the introduction of a competing brand. In turn, the own-price effects of the new entrant exhibit a gradually declining persistence level.

An alternative approach, proposed by Pauwels and Hanssens (2004), examines mature markets in moving windows of fifty-two successive weeks. Even though the market is stationary over a long time sample, distinct windows of upward and downward performance trends may be found. These windows are of brief duration compared to the prevailing regime of stationary performance, at the primary demand level as well as the individual brand level. The authors conclude that products markets behave as a punctuated equilibrium, and that the occasional punctuations are uniquely associated with changes in brands' marketing regimes. Both the dynamic impulse response function and the moving windows approach support the notion that important aspects of marketing effectiveness are indeed time or occasion dependent, opening a whole new set of research opportunities.

\section{Conclusion}

Even though time-series techniques have made several noteworthy contributions to the advancement of marketing knowledge, numerous challenges remain. Several of them were elaborated upon in the preceding sections, but this list is by no means exhaustive. It is our hope that the research opportunities identified in the current article, in combination with the various presentations at the first annual "Modeling Marketing Dynamics by Time Series Econometrics" conference at the Tuck School, will accelerate the diffusion of these techniques into the marketing community.

\section{Notes}

1. See e.g., Dekimpe and Hanssens (2004b, Appendix A) for a recent review.

2. The first two challenges (i.e., how to cope with, respectively, the recent data richness and the Lucas critique), will be illustrated using examples from the recent VAR-based literature. However, these issues also apply to other (perhaps less well-known) techniques as Kalman filtering and spectral analysis. A third major challenge for TS modelers in marketing will therefore be to expand the scope of TS techniques to increasingly include those techniques, as discussed in more detail in Section 3.

3. Not surprisingly, this scanner-based data explosion has lead to many TS applications in the fast moving consumer goods (FMCG) domain. However, other applications have exploited the growing data availability on 
durable goods (e.g., Deleersnyder et al., 2004, Pauwels et al., 2004b), prescription drugs (Mizik and Jacobson, 2004a), and auctions (Jap and Naik, 2004), among others.

4. Interestingly, the increase in the number of data points is driven mostly by the higher sampling frequency, much more than by an increase in the time span covered with the data. This is unfortunate, as the former hardly contributes to an increase in the statistical power of the tests to infer long-run evolution (unit-root tests) and long-run equilibria (cointegration tests). See e.g., Hakkio and Rush (1991) for an in-depth discussion on this issue.

5. For another marketing application of this pooling approach, see Pauwels and Srinivasan (2004).

6. An in-depth discussion on the relative merits of structural models with less flexible dynamic effects on the one hand versus more flexible, reduced-form, time-series models on the other hand, is beyond the scope of the current paper. We refer the reader to various recent studies relevant to that discussion, such as Bronnenberg et al. (2005), Dubé et al. (2004), Franses (2005a, b) and Van Heerde et al. (2005).

7. Indeed, rather than a priori imposing a given structure, initial TS specifications were typically derived from sample-based summary statistics, while their superior forecasting performance was often used to motivate the use of time-series techniques (see e.g., Geurts and Ibrahim, 1975; Helmer and Johansson, 1977).

8. This growing interest is reflected both in the research priorities of the Marketing Science Institute and in the October 2004 special issue of the Journal of Marketing; see the guest editorial (Lehmann, 2004).

\section{References}

Allenby, Greg M. and Peter E. Rossi. (1991). "There is no Aggregation Bias: Why Macro Logit Models Work," Journal of Business and Economic Statistics 9, 1-14.

Andrews, Rick L. and Imran S. Currim. (2004). "An Experimental Investigation of Scanner Data Preparation Strategies for Consumer Choice Models," Working Paper Series, University of California Irvine Graduate School of Management.

Bronnenberg, Bart J., Vijay Mahajan, and Wilfried R. Vanhonacker. (2000). "The Emergence of Market Structure in New Repeat-Purchase Categories: The Interplay of Market Share and Retailer Distribution," Journal of Marketing Research 37(1), 16-31.

Bronnenberg, Bart J., Carl F. Mela and William Boulding. (2004). "The Periodicity of Competitor Pricing," Working Paper.

Bronnenberg, Bart J., Peter E. Rossi, and Naufel J. Vilcassim. (2005). "Structural Modeling and Policy Simulation," Journal of Marketing Research (forthcoming).

Brown, R. L., J. Durbin, and J. M. Evans. (1975). "Techniques of Testing the Constancy of Regression Relationships over Time," Journal of the Royal Statistical Society, Series B 37, 141-192.

Christen, Markus, Sachin Gupta, John Porter, Richard Staelin, and Dick R. Wittink. (1997). "Using MarketLevel Data to Understand Promotional Effects in a Non-Linear Model," Journal of Marketing Research 34(3), 322-334.

Dekimpe, Marnik G., and Dominique M. Hanssens. (1995). "The Persistence of Marketing Effects of Sales," Marketing Science 14(1), 1-21.

Dekimpe, Marnik G. and Dominique M. Hanssens. (1999). "Sustained Spending and Persistent Response: A New Look at Long-Term Marketing Profitability,” Journal of Marketing Research 36(4), 397-412.

Dekimpe, Marnik G. and Dominique M. Hanssens. (2000). "Time-series Models in Marketing: Past, Present and Future," International Journal of Research in Marketing 17(2-3), 183-193.

Dekimpe, Marnik G., and Dominique M. Hanssens. (2004a). "New Challenges in Marketing Time Series Modeling," Paper presented at the first "Modeling Marketing Dynamics by Time Series Econometrics" Conference, Tuck School of Business at Dartmouth, September 2004.

Dekimpe, Marnik G. and Dominique M. Hanssens. (2004b). "Persistence Modeling for Assessing Marketing Strategy Performance,” In Christine Moorman and Donald R. Lehmann (eds.), Assessing Marketing Strategy Performance. Cambridge, MA: Marketing Science Institute.

Dekimpe, Marnik G., Dominique M. Hanssens, and Jorge M. Silva-Risso. (1999). "Long-run Effects of Price Promotions in Scanner Markets," Journal of Econometrics 89(1-2), 269-291. 
Deleersnyder, Barbara, Geyskens Inge, Katrijn Gielens, and Marnik G. Dekimpe. (2002). "How Cannibalistic is the Internet Channel? A Study of the Newspaper Industry in the United Kingdom and The Netherlands," International Journal of Research in Marketing 19(4), 337-348.

Deleersnyder, Barbara, Marnik G. Dekimpe, Miklos Sarvary, and Philip M. Parker. (2004). "Weather Tight Economic Times: The Sales Evolution of Consumer Durables over the Business Cycle," Quantitative Marketing and Economics (forthcoming).

Dubé, Jean-Pierre, K. Sudhir, Andrew Ching, Gregory S. Crawford, Michaela Draganska, Jeremy T. Fox, Wesley Hartmann, Günter J. hitsch, V. Brian Viard, Miguel Villas-Boas, and Naufel Vilcassim. (2004). "Recent Advances in Structural Econometric Models: Dynamics, Product Positioning and Entry," Marketing Letters (forthcoming).

Durbin, J. and S. J. Koopman. (2001). Time Series Analysis by State Space Methods. Oxford, U.K: Oxford University Press.

Fok, Dennis, Csilla Horváth, Richard Paap, and Philip Hans Franses. (2004). "A Hierarchical Bayes Error Correction Model to Explain Dynamic Effects of Promotions on Sales,” Working Paper, Erasmus University Rotterdam.

Forsberg, L. and Eric Ghysels. (2004). "Why do Absolute Returns Predict Volatility so Well?” Discussion Paper UNC.

Franses, Philip Hans. (2005a). “On the Use of Marketing Models for Policy Simulation,” Journal of Marketing Research (forthcoming).

Franses, Philip Hans. (2005b). "Diagnostics, Expectations and Endogeneity," Journal of Marketing Research, (forthcoming).

Geurts, Michael D. and I.B. Ibrahim. (1975). "Comparing the Box-Jenkins Approach with the Exponentially Smoothed Forecasting Model Application to Hawaii Tourists," Journal of Marketing Research 12, 182-188.

Ghysels, Eric. (2004). "MIDAS Regressions," Paper Presented at the first "Modeling Marketing Dynamics by Time Series Econometrics" Conference, Tuck School of Business at Darthmouth College, September 2004.

Ghysels, Eric, Pedro Santa-Clara, and Rossen Volkanov. (2003a). “The MIDAS Touch: Mixed Data Sampling Regressions," Discussion paper UNC and UCLA.

Ghysels, Eric, Pedro Santa-Clara, and Rossen Volkanov. (2003b). "There is a Risk-Return Trade-Off After All," Journal of Financial Economics (forthcoming).

Ghysels, Eric, Pedro Santa-Clara and Rossen Volkanov. (2003c). "Predicting Volatility: How to Get Most out of Returns Data Sampled at Different Frequencies," Journal of Econometrics (forthcoming).

Hakkio, C.S. and M. Rush. (1991). "Cointegration: How Short is the Long Run,” Journal of International Money and Finance 10, 571-581.

Hanssens, Dominique M. and Henry A. Levien. (1983). “An Econometric Study of Recruitment Marketing in the U.S. Navy," Management Science.

Hanssens, Dominique M., Leonard J. Parsons, and Randall L. Schultz. (2001). Market Response Models: Econometric and Time Series Analysis, 2nd Edition. Kluwer Academic Publishers.

Helmer, Richard M. and Johny K. Johansson. (1977). "An Exposition of the Box-Jenkins Transfer Function Analysis with an Application to the Advertising-Sales Relationship," Journal of Marketing Research 14, 227 239.

Horváth, Csilla and Jaap E. Wieringa. (2003). "Combining Time Series and Cross-Sectional Data for the Analysis of Dynamic Marketing Systems," University of Groningen. Working Paper.

Jap, Sandy D. and Prasad A. Naik. (2003). "Estimating Bid-price Distributions in Online Reverse Auctions for Industrial Procurement," Paper presented at the first "Modeling Marketing Dynamics by Time Series Econometrics" Conference, Tuck School of Business at Dartmouth, September 2004.

Joshi, Amit and Dominique M. Hanssens. (2004). "Advertising Spending and Market Capitalization," Working Paper, UCLA Anderson School of Management, February.

Kadyali, Vrinda, K. Sudhir, and Vithala R. Rao. (2001). "Structural Analysis of Competitive Behavior: New Empirical Industrial Organization Methods in Marketing," International Journal of Research in Marketing 18 (1-2), 161-186

Leeflang, Peter S. H., Jaap E. Wieringa, and Dick R. Wittink. (2004). "Competitive Reaction- and Feedback Effects Based on VARX Models of Pooled Store Data," University of Groningen. Working Paper.

Lehmann, Donald R. (2004). "Metrics for Making Marketing Matter," Journal of Marketing 68(Oct.), 73 75. 
Leone, R. (1985). "Generalizing What is Known about Temporal Aggregation and Advertising Carryover," Marketing Science 14(3), 141-150.

Lemmens, Aurélie, Christophe Croux, and Marnik G. Dekimpe. (2004). "Decomposing Granger Causality over the Spectrum," Working Paper, Erasmus University Rotterdam.

Lemmens, Aurélie, Christophe Croux, and Marnik G. Dekimpe. (2005). "On the Predictive Content of Production Surveys," International Journal of Forecasting, (forthcoming).

Lim, Jooseop, Imran S. Currim, and Rick L. Andrews. (2004). "Consumer Heterogeneity in the Long-term Effects of Price Promotions," Paper presented at the first "Modeling Marketing Dynamics by Time Series Econometrics," Conference, Dartmouth College, September 2004.

Litterman, Robert B. (1984). "Forecasting and Policy Analysis with Bayesian Vector Autoregression Models," Federal Reserve Bank of Minneapolis Quarterly Review (Fall), 30-41.

Little, John D.C. (1979). "Aggregate Advertising Models: The State of the Art," Operations Research 29, 629-67.

Macé, Sandrine and Scott A. Neslin. (2004). "The Determinants of Pre- and Postpromotion Dips in Sales of Frequently Purchased Goods," Journal of Marketing Research 41(3), 339-350.

Mela, Carl F., Sunil Gupta, and Donald R. Lehmann. (1997). “The Long-Term Impact of Promotion and Advertising on Consumer Brand Choice," Journal of Marketing Research 34(2), 248-261.

Mizik, Natalie and Robert Jacobson. (2004a). "Are Physicians 'Easy Marks'? Quantifying the Effects of Detailing and Sampling on New Prescriptions," Management Science 50(12).

Mizik, Natalie and Robert Jacobson. (2004b). "Myopic Management and the Need for Marketing Metrics: The Case of the Seasoned Equity Offering," Paper presented at the first "Modeling Marketing Dynamics by Time Series Econometrics" Conference, Tuck School of Business at Dartmouth, September 2004.

Naik, Prasad A. (1999). "Estimating the Half-life of Advertisements," Marketing Letters 10(3), 351-362.

Naik, Prasad, Murali Mantrala, and Alan Sawyer. (1998). "Planning Media Schedules in the Presence of Dynamic Advertising Quality," Marketing Science 17(3), 214-235.

Naik, Prasad A. and Kalyan Raman. (2003). "Understanding the Impact of Synergy in Multimedia Communications," Journal of Marketing Research 34(2), 248-261.

Prasad A. Naik, Kalyan Raman, and Russell S. Winer. (2005). "Planning Marketing-Mix Strategies in the Presence of Interaction Effects: Empirical and Equilibrium Analysis," Marketing Science (forthcoming).

Nijs, Vincent R., Marnik G. Dekimpe, Jan-Benedict E.M. Steenkamp and Dominique M. Hanssens. (2001). "The Category-Demand Effects of Price Promotions," Marketing Science 20(1) 1-22.

Parsons, Leonard J. (1975). "The Product Life Cycle and Time-Varying Advertising Elasticities," Journal of Marketing Research 12 (Nov.), 476-80.

Pauwels, Koen. (2004). "How Dynamic Consumer Response, Competitor Response, Company Support and Company Inertia Shape Long-Term Marketing Effectiveness," Marketing Science 23(4), 596-610.

Pauwels, Koen, Dominique M. Hanssens, and Sivaramakrishnan Siddarth. (2002). "The Long-Term Effect of Price Promotions on Category Incidence, Brand Choice and Purchase Quality," Journal of Marketing Research 39(4), 421-439.

Pauwels, Koen, and Dominique M. Hanssens. (2004). "Performance Regimes and Marketing Policy Shifts,“ Working Paper, UCLA Anderson School of Management, October.

Pauwels, Koen, Prasad A. Naik, and Carl F. Mela. (2004a). "A Factor VAR Model of SKU Sales and Prices,"Paper presented at the first "Modeling Marketing Dynamics by Time Series Econometrics" Conference, Tuck School of Business at Dartmouth.

Pauwels, Koen, Jorge Silva-Risso, Shuba Srinivasan, and Dominique M. Hanssens. (2004b). "New Products, Sales Promotions and Firm Value: The Case of the Automobile Industry," Journal of Marketing 68(Oct.), 142 156.

Pauwels, Koen and Shuba Srinivasan. (2004). "Who Benefits from Store Brand Entry?” Marketing Science 23(3), 364-390.

Pesaran, M. Hashem, and Ronal P. Smith. (1995). "Estimating Long-run Relationships from Dynamic Heterogeneous Panels," Journal of Econometrics 68(1), 79-113.

Priestley, Maurice B. (1981). Spectral Analysis and Time Series, Wiley.

Sasieni, Maurice. (1971). “Optimal Advertising Expenditure," Management Science 18 (Dec.), 64-72.

Sasieni, Maurice. (1989). "Optimal Advertising Strategies," Marketing Science 8, (December), 358-370. 
Shumway, Robert H., David S. Stoffer. (2000). Time Series Analysis and its Applications. Springer-Verlag, Inc.: New York, N.Y.

Simon, Hermann. (1982). “ADPULS: An Advertising Model with Wearout and Pulsation,” Journal of Marketing Research 19(3), 352-363.

Srinivasan, Shuba, Koen Pauwels, Dominique M. Hanssens, and Marnik G. Dekimpe. (2004). "Do Promotions Benefit Manufacturers, Retailers or Both?" Management Science 50(5), 617-629.

Srinivasan, Shuba, Koen Pauwels, and Vincent Nijs. (2003). "Retail Price Drivers and Their Financial Consequences," Working Paper, Tuck School of Business at Dartmouth.

Steenkamp, Jan-Benedict E.M., Vincent R. Nijs, Dominique M. Hanssens, and Marnik G. Dekimpe. (2004). "Competitive Reactions to Advertising and Promotion Attacks," Marketing Science (forthcoming).

Tellis, Gerard, and Philip H. Franses. (2004). "Optimal Data Interval For Econometric Models of Advertising Carryover," Paper presented at the first “Modeling Marketing Dynamics by Time Series Econometrics," Conference, Tuck School of Business at Dartmouth, September 2004.

Van Heerde, Harald J., Marnik G. Dekimpe, and William P. Putsis Jr. (2005). "Marketing Models and the Lucas Critique," Journal of Marketing Research (forthcoming).

Wieringa, Jaap E., and Csilla Horváth. (2004). "Impulse Response Analysis of Structural Vector Autoregressive Log-transformed Time Series," International Journal of Forecasting (forthcoming).

Yoo, Shijin and Dominique M. Hanssens. (2004). "The Long-Term Effects of Marketing on Customer Equity: From Relationship to Product Marketing," UCLA Anderson School of Management, Working Paper.

Yoo, Shijin. (2004). "Dynamic Impulse Response Functions," Working Paper, Singapore Management University. Zanutto, Elaine, and Eric T. Bradlow. (2001). "The Perils of Data Pruning in Consumer Choice Models," The Wharton School of the University of Pennsylvania, Working Paper. 